\title{
Benefiting from Wrongdoing and Sustaining Wrongful Harm
}

\author{
Christian Barry \\ Director, Centre for Moral, Social, and Political Theory (СMSPT) \\ School of Philosophy, Research School of Social Sciences, \\ Australian National University \\ christian.barry@anu.edu.au
}

David Wiens

Assistant Professor, Department of Political Science

Fellow, Center on Global Justice, University of California, San Diego

dwiens@ucsd.edu

\begin{abstract}
Some moral theorists argue that innocent beneficiaries of wrongdoing may have special remedial duties to address the hardships suffered by the victims of the wrongdoing. These arguments generally aim to simply motivate the idea that being a beneficiary can provide an independent ground for charging agents with remedial duties to the victims of wrongdoing. Consequently, they have neglected contexts in which it is implausible to charge beneficiaries with remedial duties to the victims of wrongdoing,
\end{abstract}

Christian Barry is Associate Professor of Philosophy and the Director of the Centre for Moral, Social, and Political Theory at the Australian National University. His research focuses on ethical theory, philosophy of action, and international justice. His recent work includes a monograph with Sanjay Reddy, International Trade and Labour Standards: A Proposal for Linkage (Columbia University Press), and articles in Philosophy \& Public Affairs, Journal of Political Philosophy, Politics, Philosophy and Economics, Review of International Studies, International Affairs, and Journal of Applied Philosophy. He is currently completing a book with Gerhard Øverland for Cambridge University Press on the meaning and moral significance of the distinctions between doing, allowing, and enabling harm. He earned his PhD in philosophy from Columbia University.

David Wiens is Assistant Professor of Political Science at the University of California, San Diego and a Fellow at the Center on Global Justice at UCSD. Before arriving at UCSD, he was Postdoctoral Research Fellow at the School of Philosophy at the Australian National University. He earned his $\mathrm{PhD}$ in philosophy from the University of Michigan. 
thereby failing to explore the limits of the benefiting relation in detail. Our aim in this article is to identify a criterion to distinguish contexts in which innocent beneficiaries plausibly bear remedial duties to the victims of wrongdoing from those in which they do not. We argue that innocent beneficiaries incur special duties to the victims of wrongdoing (qua beneficiary) if and only if receiving and retaining the benefits sustains wrongful harm. We develop this criterion by identifying and explicating two general modes of sustaining wrongful harm. We also show that our criterion offers a general explanation for why some innocent beneficiaries incur a special duty to the victims of wrongdoing while others do not. By sustaining wrongful harm, beneficiarieswith-duties contribute to wrongful harm, and we ordinarily have relatively stringent moral requirements against contributing to wrongful harm. On our account, innocently benefiting from wrongdoing per se does not generate duties to the victims of wrongdoing. Rather, beneficiaries acquire such duties because their receipt and retention of the benefits of wrongdoing contribute to the persistence of the wrongful harm suffered by the victim. We conclude by showing that our proposed criterion also illuminates why there can be reasonable disagreement about whether beneficiaries have a duty to victims in some social contexts.

\section{Keywords}

benefiting from injustice - contribution-based responsibility - harm - obligations

\section{Introduction}

When people commit wrongs against others, this often gives rise not only to harm to their victims, but also to benefits. Some of these benefits accrue not to the wrongdoer, but to people who are innocent of any wrongdoing whatsoever. Some moral theorists argue that merely being an innocent beneficiary of others' wrongdoing may be sufficient to ground special duties to address the hardships suffered by the victim of the wrongdoing, at least when it is impossible to extract compensation from the wrongdoer. ${ }^{1}$ We can call such duties 'benefiting-based duties,' since the mere fact of benefiting from wrongdoing is

1 Daniel Butt, 'On Benefiting from Injustice,' Canadian Journal of Philosophy 37 (2007), pp. 129-152; Robert Goodin, 'Disgorging the Fruits of Historical Wrongdoing,' American Political Science Review 107 (2013), pp. 478-491; Judith Thomson, 'Preferential Hiring,' Philosophy \& Public Affairs 2 (1973), pp. 364-384; Holly Lawford-Smith, 'Benefiting from Failures to Address Climate Change,' Journal of Applied Philosophy. 
meant to provide an independent ground for the duties. Investigating whether there are any benefiting-based duties seems important, since it is often the case that the perpetrators of wrongdoing are difficult to identify or they are not in a position to compensate the victims to an adequate extent.

There are numerous contexts in which innocent beneficiaries of wrongdoing have duties. Here's one:

Stolen Car. Bill steals John's car and gives it to Susan, who is innocent of any wrongdoing herself. Bill can no longer be found, nor does he leave behind assets that can be seized.

Susan has a duty to address the hardships John suffers as a result of the wrongdoing from which she benefits; in the first instance, she needs to return the car (or something of equivalent value, if the car can no longer be returned). ${ }^{2}$ She would certainly not have a duty to give him a car had she not received his car. We'll call such cases benefiting-with-duty cases.

There are other contexts in which benefiting from another person's wrongdoing apparently fails to create a special obligation to address the victim's hardships. Consider this case:

Terrorist Bombing. A terrorist sets off a bomb, which grievously injures several people. To avoid the explosion, Bill retreats to a nearby cafe, where he meets Susan. Their chance meeting eventually gives rise to an extremely lucrative business partnership. The terrorist cannot be found nor has he left behind assets that can be seized.

It seems far-fetched to claim that the benefits Bill and Susan receive generate special duties to mitigate the hardships of the victims of the blast (except insofar as their additional income makes it easier for them to assist these people). ${ }^{3}$ That is, they have no special duty to the victims in virtue of receiving benefits from the wrongdoing. Call such cases benefiting-without-duty cases.

Our aim in this article is to identify a criterion to distinguish contexts in which innocent beneficiaries of wrongdoing benefit-with-duty from those in which they benefit-without-duty. To foreshadow our conclusions, we deny that

2 There may of course be circumstances under which we would excuse Susan from paying at least some portion of this cost; for instance, when she has innocently made plans and commitments on the basis of the possession of the car that it would now be very costly for her to break. We discuss such excusing conditions at length below.

3 Thanks to Garrett Cullity for this case. 
the mere reception of benefits from wrongdoing is sufficient to ground special remedial duties to the victims of wrongdoing. Simply put, benefiting from wrongdoing is not a sui generis moral category and there are no benefitingbased duties as such. Yet, given some benefiting-with-duty cases, we acknowledge benefiting-related duties, duties that can be triggered by the fact of benefiting from wrongdoing in certain circumstances without being grounded in the fact of benefiting. We argue that innocent beneficiaries incur benefitingrelated duties to the victims of wrongdoing - that is, people benefit-withduty-if and only if receiving and retaining the benefits sustains wrongful harm. (Let us be clear: we argue that sustaining wrongful harm is a necessary condition solely for benefiting-related duties. There are surely bases for special remedial duties for which sustaining wrongful harm is not a necessary condition-e.g., a capacity to assist or having done the initial harm.) By 'wrongful harm' we mean the unjustified harm suffered by a victim that ensues from a wrongful act. For our purposes, this category includes cases where a person's right is violated without any corresponding decrease in their welfare. We explain two general modes by which an innocent beneficiary can sustain wrongful harm. ${ }^{4}$ First, an innocent beneficiary sustains wrongful harm if she receives and retains an item or quantum of value to which another person has a justified claim. Second, an innocent beneficiary sustains wrongful harm if she receives and retains benefits derived from advantages conferred by a social practice or institution in violation of another person's justified claim(s) against that practice or institution. ${ }^{5}$

In addition to providing a plausible principle of distinction, our criterion yields a general explanation for why innocently receiving benefits from wrongdoing sometimes triggers a duty to the victims of wrongdoing while other times it does not. When innocent beneficiaries sustain wrongful harm, they make a distinctive kind of contribution to wrongful harm (albeit not the initial harm that was inflicted on the victim by the wrongdoer), and we have relatively stringent moral requirements not to contribute to wrongful harm. On our account, then, merely receiving benefits from wrongdoing is insufficient to generate remedial duties to the victims of wrongdoing. Thus, there are

4 Since we are interested in determining the conditions under which otherwise innocent people benefit-with-duty, we only define the sustaining category as it relates to the innocent reception of benefits from wrongdoing. Our account of sustaining wrongful harm is, thus, not a complete account of that relation. A full account of the ways in which people (beneficiary or not) can sustain harm is an interesting project, but one that we cannot undertake here.

5 Whenever we refer to claims hereafter we mean justified claims. 
no benefiting-based duties perse. Instead, it is because their receipt and retention of the benefits of wrongdoing contributes to the persistence of wrongful harm that otherwise innocent beneficiaries incur remedial duties.

Throughout, we appeal to our readers' considered moral judgments about simple cases as our starting point, aiming to achieve a reflective equilibrium between these judgments and the theoretical account we propose. We recognize that there are instances in which our account may conflict with some people's considered judgments. When this is so, we try to show that there is nevertheless reason to accept our account as a stable equilibrium point. Further, we conclude by showing that our proposed criterion can illuminate reasonable disagreement about whether beneficiaries have a duty to victims in some social contexts.

Our aims in this essay are limited in three important respects. First, we are solely concerned with the conditions under which materially benefiting from wrongdoing triggers special duties to the victims of that wrongdoing; we set aside other reasons why a beneficiary might bear a duty to the victim. ${ }^{6}$ Hence, we assume throughout that the beneficiaries in question do not contribute in any way to the initial wrongdoing from which they benefit and that they do not bear any special relationship to the victim. We also assume that the beneficiaries are not culpable in any way in their reception of benefits; for instance, they do not knowingly receive stolen goods. (We'll generally leave off the 'innocent' qualification hereafter.)

Second, we focus on what we shall call remedial duties. That is, we ask whether those who innocently benefit from the wrongdoings in question thereby acquire duties to compensate the victims of wrongdoing for their losses or to act on their behalf to rectify the wrongful state. ${ }^{7}$ We leave aside

6 We also set aside nonmaterial benefits, such as romantic love. This is not because such benefits are unimportant. Rather, it is because they seem to raise distinct issues and thus may require separate treatment. With respect to a good like romantic love, for example, it is unclear that one could ever have a duty to relinquish it or compensate others as a result of receiving it, regardless of the process that gave rise to it (though of course one could do things to other people as a means of obtaining it that could lead to their having remedial obligations.) Moreover, discussions of benefiting from injustice have focused nearly exclusively on material benefits, so shedding light even on this subset of cases would be a contribution to this debate.

7 On remedial duties, see David Miller, 'Distributing Responsibilities,' Journal of Political Philosophy 9/4 (2001), pp. 453-471. These duties are prima facie, in that what an agent has reason to do, all things considered, may be to act against them. Nevertheless, in acting against them, the agent retains a reason to act on them in the future-a moral reminder of his failure to discharge this duty [cf. William D. Ross, The Right and the Good (Oxford: Oxford University Press, 1930). 
other types of duties, for instance: duties to express sympathy to or solidarity with the victims, or duties to simply disgorge the benefits, whether they are returned to the victim or not. Our inquiry concerns the conditions under which benefiting from wrongdoing triggers a remedial duty to the victim. Third, we are concerned with the duties beneficiaries have to the victims of the wrongdoing from which they benefit. Our interest here concerns when benefiting from wrongdoing changes the beneficiary's moral position vis-a-vis the victim of the wrongdoing, causing them to acquire directed duties to the victim. Thus, we do not consider what the beneficiary of wrongdoing must do when the victim is no longer around (e.g., she dies as a consequence of the wrongdoing). ${ }^{8}$

Moral theorists who have discussed the issue of benefiting from wrongdoing (simply 'benefiting' hereafter) have generally focused on benefiting-with-duty cases to motivate the idea that simply being a beneficiary can provide an independent ground for charging agents with remedial duties to the victims of wrongdoing. ${ }^{9}$ However, they have not explored the limits of the benefiting relation in detail. At least, we have not found explicit proposals in the literature for a criterion to distinguish benefiting-with-duty cases from benefitingwithout-duty cases. Those who are skeptical of the idea of remedial duties based on benefiting have tried to assimilate benefiting-with-duty cases to the simpler, and much more familiar, idea of restitution. So one possible criterion for distinguishing the cases that concern us is that innocent beneficiaries bear remedial duties only when the victims of the wrongdoing have a claim of restitution against them. Stolen Car is certainly a case that can be explained in this way, and it might be tempting to think that all cases of benefiting-with-duty are of this sort. 10

8 For a related discussion, see Goodin, 'Disgorging the Fruits of Historical Wrongdoing,' pp. $478-491$.

9 Butt, 'On Benefiting from Injustice,' pp. 129-152; Thomas Pogge, World Poverty and Human Rights: Cosmopolitan Responsibilities and Reforms (Cambridge: Polity and Malden MA: Blackwell, 2002).

10 Norbert Anwander, 'Contributing and Benefiting: Two Grounds for the Duties to Victims of Injustice,' Ethics \& International Affairs 19 (2005), pp. 39-45; Robert K. Fullinwider, 'Preferential Hiring and Compensation,' Social Theory \& Practice 3 (1975), pp. 307-320. In an interesting recent paper Carl Knight, 'Benefiting from Injustice and Brute Luck,' Social Theory \& Practice 39 (2013), pp. 581-598 suggests that benefiting-based duties can 
Restitution is called for, in the first instance, when there is some particular good to which the victim of the wrongdoing has a claim, and this good ends up in the possession of the beneficiary. This is true of Susan in Stolen Car. The idea of restitution can be extended to cover goods to which the victim has a claim, but which are not identical to the goods that were initially misappropriated. If Susan subsequently sells John's car, it may be the proceeds from the sale, and not the car, to which John has a claim in restitution (if the car cannot now be recovered). Susan has converted the thing taken (car) into a different value (cash), and it is this quantum of value to which John now has a claim, rather than the initial thing of which he was wrongfully dispossessed. ${ }^{11}$

The common law notion of 'tracing' illustrates how a principle of restitution can be plausibly extended. Tracing is the exercise of identifying an asset that ought to be treated as 'standing in' for some other item to which a person has a claim. ${ }^{12}$ Tracing is distinct from 'following,' which is the process of physically tracking some particular item to which a person has a claim. To illustrate, consider the following variation on Stolen Car:

Unwanted Car. Bill steals John's car. Realizing that he no longer needs the car he already owns, Bill gives his old car to Susan. (Susan remains innocent of any wrongdoing). ${ }^{13}$

Here, Bill takes something to which John has a claim: his car. Susan clearly benefits from Bill's wrongdoing, but she does not hold John's car. A principle of restitution can explain this. It is true that in the first instance John has a claim

be explained away by luck egalitarianism. His idea is that special obligations assigned to those with good brute luck can explain judgments about cases where beneficiaries of injustice have remedial duties to victims. There are two significant challenges for Knight's account. First, it cannot explain the directed nature of beneficiaries' duties. On his account, someone who benefits from good brute luck has a duty to redistribute those benefits to anyone with bad brute luck, not only to the victim of the wrongdoing that resulted in the benefits received. Second, Knight doesn't provide a criterion of distinction; his account treats all cases of benefiting from wrongdoing as benefiting-with-duty cases (even in Terrorist Bombing, Bill and Susan benefit from good brute luck). Insofar as one thinks that benefiting-related duties are directed and that there are benefiting-without-duty cases, Knight's account will be unpersuasive.

11 Richard Nolan, 'Change of Position,' in P. Birks (ed.), Laundering and Tracing (Oxford: Clarendon Press, 1995); Lionel Smith, 'Restitution,' in P. Cane and M. Tushnet (eds.), Oxford Handbook of Legal Studies (Oxford: Oxford University Press, 2003).

12 Smith, 'Restitution.'

13 This case is presented in Bashshar Haydar and Gerhard Øverland, 'Benefiting from Injustice and Poverty Alleviation,' Journal of Applied Philosophy (Forthcoming). 
to his car. But when Bill violates this claim, John is also entitled to the quantum of value represented by the car, in case the car itself is no longer recoverable. If, for example, Bill were instead to sell John's car to a spare parts yard in exchange for money, John would nevertheless retain a claim against Bill for (at least) its full value. Bill would be duty-bound to give John the proceeds of selling John's car. And if Bill were to give some of the proceeds of his sale to Susan as a gift, then John can demand this money from Susan because it too is traceable to his car. Unwanted Car differs from this case only in the fact that what Bill gives to Susan is not money, but a car. In this case, the used car Bill gives to Susan can be traced to John's car; John's claim to his car thus grounds a claim to the car Susan now holds (in the absence of his own car). Accordingly, Susan holds an asset to which John has a claim. More generally, suppose Bill's assets and liabilities prior to the theft add up to B; upon stealing John's car, Bill's total assets swell to $\mathrm{B}+\mathrm{J}$. John has a claim on Bill's total assets equal to J. If (and only if) Susan receives a portion of $\mathrm{B}+\mathrm{J}$ to which she does not have a prior claim (e.g., she does not receive payment on a debt Bill owes to her), then John has a claim on the assets Susan receives up to the amount J (assuming he cannot recover J from Bill). Thus, a principle of restitution is general enough to explain why Unwanted Car is an instance of benefiting-with-duty.

This does not mean that John's claim with respect to Susan's assets will persist indefinitely. Once Susan (innocently) begins to plan and orient her life around the car, such that returning the amount of John's initial claim would leave her worse off than she would be without having received the car in the first place, then this 'change of position' can weaken or in some cases even eliminate John's claim to compensation from Susan. ${ }^{14}$ (Things are quite different if Susan is culpable in some way for receiving and retaining the proceeds of Bill's theft. Even if she only suspects that there might be something suspicious about the origins of this gift, then she cannot plausibly defend her assets at a later time on the ground that she made plans on the assumption that they were rightfully hers.) What happens if Bill sells his old car after the theft and sends some of the proceeds to several other people? In this case John would have claims on the assets of all of those who receive the proceeds (assuming, again, that he cannot recover directly from Bill).

This sort of restitution-style analysis is quite powerful, and can no doubt explain many cases of benefiting-with-duty. However, it is inadequate as a general criterion for distinguishing cases of benefiting-with-duty from cases of benefiting-without-duty because it is under inclusive. There are many contexts in which benefiting-with-duty applies where the victim fails to have a claim to

14 Elise Bant, The Change of Position Defence (Oxford: Hart, 2009).

JOURNAL OF MORAL PHILOSOPHY (2014) 1-23 
any particular thing or quantum of value that the beneficiary has received. Consider this case:

No Promotion. Senior members of a law firm create a work environment that systematically disadvantages women in seeking promotion to senior positions.

In this case, one or more of the firm's practices violate a claim that the women have against the firm — namely, that it not maintain practices that systematically disadvantage women in competition for promotion or other benefits of employment. It may be that no particular woman in the firm has a claim to any particular senior position (we may be uncertain about which individuals would have received a promotion under a fair procedure). If so, it will not be the case that any men in the firm have received a tangible item or quantum of value to which any woman in the firm has a claim. Thus, no one would be owed restitution, even when this notion is broadly understood. Nevertheless, it is clear that at least some men in the firm benefit from the firm practices that wrong the women and it seems plausible that, by receiving those benefits, they incur a duty to these women to remedy the wrongful situation - a duty additional to any general duty to assist victims of wrongdoing.

Just which benefits could trigger the men's duty to the firm's women? They may vary from person to person. All of the men in the firm gain a competitive advantage over women in seeking promotion. ${ }^{15}$ Some of them receive in addition the material benefit of actually being promoted through the process that afforded them this competitive advantage. And of those men who are promoted, it may be that some of them would not have received this benefit without the discriminatory procedure. ${ }^{16}$

One might think that insofar as some of the men who were promoted through the discriminatory practice would have been promoted even without it, they would lack a special remedial duty to the women in the firm. But this is implausible. When some benefit is conferred as a result of wrongdoing, the fact that the benefit would or could have been received even without the wrongdoing does not defeat the claims of those wronged. For example, if one firm receives a government contract as a result of bribery paid by a third party,

15 Recall our assumption that the men are innocent in their reception of these advantages. Perhaps the discrimination is subtle enough as to be opaque to them.

16 The differences in the degree and manner in which particular men in the firm benefit from the injustice to women may affect the precise nature of their special duties to them, a point to which we shall return below. 
then the fact that the firm would have received it anyway even without the bribery does not defeat the claims of those who lose out. At a minimum, the firm that has benefited from the bribe must be willing to submit to a new bidding process that guards against such unfair practices. Similarly, the men who were promoted could be required to submit themselves to a fresh evaluation procedure that is untainted by discrimination. ${ }^{17}$ Whether this is required, though, depends not only on the costs involved in carrying it out but also on the nature of the wrongdoing. Perhaps the firm's practices deny women effectively equal opportunities to achieve the credentials required to qualify for a promotion, by offering to pay for special training courses only to men. If that were so, then the wrong inflicted on them is not limited to a discriminatory evaluative procedure for determining who should be promoted. Since, in a new evaluation, men would likely come out as the most qualified given the background injustice engendered by the firm's practices, the promoted men would continue to receive the benefit of a promotion in violation of the women's claims against the firm, namely, that the firm not deny women equal opportunities for advancement.

Two points are worth emphasizing. The precise content of beneficiaries' duties will differ depending on the nature of the benefits conferred to them and the nature of the wrongdoing that generates the benefits. More importantly for our purpose here, owing restitution is not necessary for a beneficiary to have a special remedial duty to the victims of the wrongdoing. Thus, contrary to what Anwander and Fullinwider suggest, a principle of restitution will not suffice as a criterion for distinguishing benefiting-with-duty cases from benefiting-without-duty cases.

Although it cannot account for contexts where beneficiaries seem to have a special duty to victims even without receiving anything to which any particular victim has a claim, the restitution principle nonetheless captures something important. Where restitution applies, the beneficiary has a duty to the victim of the wrongdoing because the beneficiary's receipt and subsequent retention of the benefit sustains a state of affairs wherein the victim's claim to

17 We write 'could be,' rather than 'must' since there may be circumstances (as noted in fnı above and below in our discussion of Driveway) in which imposing such a requirement would be excessively costly for all concerned and thus is not justified, all things considered. 
the item received remains unresolved - they continue to be in a condition of suffering wrongful harm. The problem with restitution as a criterion of distinction is that it is too narrow-a person can sustain wrongful harm without receiving an item or quantum of value to which any victim of the wrongdoing has a claim. Generalizing this insight, we propose the following criterion for distinguishing benefiting-with-duty cases from benefiting-without-duty cases:

An innocent beneficiary of wrongdoing owes a benefiting-related remedial duty to the victim(s) of the wrongdoing if and only if the beneficiary's receipt and subsequent retention of the benefits from the wrongdoing sustains wrongful harm.

In the remainder of this section, we develop and explain this criterion by identifying and making precise two ways in which beneficiaries can sustain wrongful harm. Along the way, we consider cases that might appear to be counterexamples to our sufficiency claim, and show why we do not think they provide good reasons to reject it. We turn to defending our necessity claim in the next section.

There are two general ways in which beneficiaries can sustain harm. ${ }^{18}$ The first is best illustrated through cases where restitution applies. Beneficiaries sustain wrongful harm in these cases if their receipt and subsequent retention of an item or quantum of value to which the victim has a claim sustains a state of affairs wherein the victim's claim remains unresolved. To illustrate the point, compare Stolen Car to Theft and Recovery:

Theft and Recovery. Bill steals John's car. He then sells it and gives the money to Susan (who is innocent of any wrongdoing). John subsequently tracks down Bill and receives compensation for his car from Bill.

In Theft and Recovery, Susan receives assets that are traceable (in the sense described above) to John's car and, thus, in violation of John's claim to his car (as in Unwanted Car). Susan does not sustain wrongful harm, however, if she keeps the money in this case, despite the fact that she receives assets in violation of John's claim. ${ }^{19}$ The reason is simple: John's claim is resolved if he is fully

18 We reiterate here that we are only concerned with the ways in which receiving and retaining the benefits of wrongdoing might sustain wrongful harm. There may of course also be ways in which non-beneficiaries might sustain wrongful harm, although we do not explore these in this paper.

19 We are here setting aside other reasons that Susan might have to disgorge the money. However, we conjecture that the judgment that innocent beneficiaries have a general 
compensated by Bill. He is no longer in a condition of wrongful harm, though it remains true that he suffered wrongful harm as a result of Bill's theft. Susan clearly has a remedial duty to John in Stolen Car and Unwanted Car; but it seems equally clear that she does not have such a duty to John in Theft and Recovery. It does not matter in this case that the wrongdoer is the one that compensates John. If the government compensated him it would still be the case that Susan no longer has a remedial duty to him. (This is not the case with the wrongdoer, since Bill may continue to have a remedial duty to John even if the government fully compensates him.) Susan might nevertheless have a remedial duty to the government or other third parties if they, and not Bill, compensate John. On our analysis, the reason why this would be so is that her retention of the benefits would be sustaining wrongful harm to those who are out of pocket as a result of compensating John. ${ }^{20}$

What matters in these cases is not that the person who suffered wrongful harm is made as well or better off than he would have been had he not suffered it, all things considered. The theft of John's car could, by chance, have led him to an unlikely meeting with someone who forever changed his life for the better, but this in no way undermines Susan's duty to him in Stolen Car and Unwanted Car. Whether or not Susan has a remedial duty depends on whether the specific wrongful harm that John suffered persists.

The second way in which a beneficiary can sustain wrongful harm is illustrated by the case No Promotion. People typically have claims relating to the social practices and institutions that structure their interactions with others. Such claims are claims on the design of the practices themselves and against those who are collectively involved in upholding them. ${ }^{21}$ Beneficiaries can sustain wrongful harm by receiving and retaining benefits that are in violation of these claims on social practices and institutions. A beneficiary receives benefits in violation of these claims to the extent that (a) the social practice or institution directly confers advantages to her, (b) she receives these benefits in

duty to disgorge innocently received benefits is undermined by consideration of cases such as Theft and Recovery. If this is correct, then merely receiving benefits from wrongdoing is insufficient to charge beneficiaries with a duty to give up the benefits. This would further illustrate the need to engage in the sort of project we have undertaken here, namely, to determine a principled way to distinguish benefiting-with-duty cases from benefiting-without-duty cases.

20 We are grateful to an anonymous reviewer for pressing us to acknowledge this possibility.

21 The importance of claims on institutions is developed and emphasized in Thomas Pogge, Realizing Rawls (Ithaca: Cornell University Press, 1989); World Poverty and Human Rights who finds this idea to be implicit in John Rawls, A Theory of Justice (Cambridge MA: Harvard University Press, 1971). 
virtue of such advantages, and (c) the advantages through which the benefits are received contravene the claims of other people on the practice or institution. For example, suppose that Oscar has a claim against society that its institutional arrangements be designed so that he and others have access to adequate employment opportunities (relative to feasible alternatives) or that he and others enjoy equal political status. If Emma receives material benefits in virtue of advantages conferred upon her through the violation of these claims-say through processes that deny Oscar equal political status - then she receives benefits in violation of Oscar's claims on the institution. Whenever someone receives benefits in violation of a person's claim(s) relating to social practices and institutions and subsequently retains those benefits without compensating the victim or working to reform the practice or institution that has given rise to these harms, she sustains the state wherein the victim's claims remain unresolved. ${ }^{22}$

To further elaborate our point here, compare No Promotion to Court Order.

Court Order. Senior members of a law firm create a work environment that systematically disadvantages women in seeking promotion to senior positions. Women in the firm file and win a lawsuit against the firm. The firm compensates the women for their losses and makes suitable reforms to their employment practices.

Prior to the court's verdict, the men in the firm receive benefits in violation of the women's claims against the firm. They do not sustain wrongful harm if they retain those benefits after the court's verdict (assuming that the actions required of the firm by the court should indeed be considered to fully compensate them-otherwise they may still sustain wrongful harm, even if to a diminished extent). The reason is that the women's claims against the firm have (by hypothesis) been resolved. And this seems correct. The men in the law firm clearly have a remedial duty to the women in No Promotion; but it does not seem that they have such a duty to the women once the women have been fully compensated. In this case, their retaining the benefits does not sustain wrongful harm, since that harm has been remediated. Note that the mere fact that the wrongful harm has been remediated does not make it the case that they are no longer beneficiaries of the initial wrongdoing. They may continue to be

22 We note that there might be multiple claims that are relevant here. Since distinct claims might have distinct normative characteristics, the content and stringency of beneficiaries' duties will plausibly differ depending on the nature of the salient claims. Since we are concerned here with an existence claim—namely, when beneficiaries have special duties to the victims of wrongdoing — we set aside these issues. 
beneficiaries of the wrongdoing, but nevertheless no longer have duties to its victims in virtue of this fact.

Note that on our account, solely gaining and retaining competitive advantages (as opposed to material benefits) in violation of others' claims against a practice or institution is insufficient to incur a benefiting-related duty to those who are competitively disadvantaged. Consider a scenario in which a university's admissions policy discriminates against women; women are free to apply, but they will not receive due consideration on meritocratic grounds. Every man who applies has a competitive advantage but it seems implausible to charge the men who are not admitted with a special remedial duty to the women who are not admitted. The men who are not admitted have the same general duty as all other men do to reform practices that discriminate on the basis of gender. The men who are admitted, in contrast, plausibly incur an additional remedial duty to the women that are not admitted because they receive material benefits through the competitive advantage that has been conferred on them in violation of the women's claims. That is, benefiting-related remedial duties are triggered in these kinds of cases when one gains an advantage in violation of another's claim against an institution and receives a material benefit through that advantage.

Drawing together our discussion in this section, we can now state our criterion more precisely.

An innocent beneficiary of wrongdoing owes a benefiting-related remedial duty to the victim(s) of the wrongdoing if and only if one of the following conditions is satisfied:

1) the beneficiary receives an item or quantum of value to which the victim of the wrongdoing has a claim and the victim's claim remains unresolved; ${ }^{23}$ or

2) the beneficiary receives a benefit in violation of the victim's claim(s) on the wrongful practice or institution and the victim's claim(s) remain unresolved.

We conjecture that sustaining wrongful harm in either of these ways is sufficient for an innocent beneficiary to incur a remedial duty to the victim(s) of the wrongdoing from which she benefits.

23 Strictly speaking, the quantum of value received need not benefit the recipient for the latter to qualify as sustaining harm. This indicates one way to generalize our sustaining criterion: we could speak throughout of 'the proceeds of wrongdoing' rather than simply 'the benefits of wrongdoing.' As we are here only interested in the ways in which beneficiaries of wrongdoing can sustain harm, we set aside further discussion on this point. 
One potential counterexample to this sufficiency claim involves the common law 'change in position' defense (mentioned above), whereby the beneficiary incorporates the benefits received into their life such that retracting them would cause severe hardship for her. For example, consider a variation of a case used by Daniel Butt: ${ }^{24}$

Driveway. You have saved $\$ 2,000$ to repave your driveway, but have not contracted a paving company. Your neighbor also needs a new driveway and has paid \$2,00o to a contractor to do the work. Your neighbor's enemy switches the numbers on your houses so that the contractor paves your driveway instead of your neighbor's. You arrive home to a newly paved driveway and a note informing you that a friend who knew of your plans has paved your driveway at their expense as a gift. Elated, you use the $\$ 2,000$ you had saved for the driveway to take your partner on a longoverdue holiday. Your neighbor's enemy cannot be located nor has she left behind assets that can be seized to compensate him.

In this case, your failing to compensate your neighbor appears to sustain the wrongful harm done to him on our account. Suppose your neighbor finds out what happens and confronts you (being unable to locate her enemy or the contractor), but you no longer have the $\$ 2$, ooo nor do you have anything that could be converted to $\$ 2,000$ without causing you great hardship. The change of position doctrine enables you to rebut your neighbor's claim to compensation; that is, his claim to the $\$ 2,000$ is mitigated or defeated by your change of position.

While we are sympathetic with regard to the considerations that support the change of position doctrine, we do not think that it serves as a counterexample to our sufficiency claim. In the case discussed, it seems implausible that you lack any special duty whatsoever to your neighbor to help cover his losses. This is not to say that you have a duty to return the full cash value of the driveway you have received. Nevertheless, it seems wrong that your neighbor should bear the entire cost that the wrongdoing has engendered, while you bear none of it. One solution might be for you and your neighbor to share the loss equally; another (as Butt suggests) is for you pay them the amount you would have been willing to pay for the driveway. But these solutions might seem implausible when this leaves the beneficiary worse off (all things considered) than they would have been had the benefit of the driveway not been conferred to them. In this case, you might be required to pay to your neighbor

24 Butt, 'On Benefiting from Injustice,' p. 40-1 (adapting an example employed by Fullinwider, 'Preferential Hiring and Compensation,' pp. 316-317. 
the amount you would have been willing to pay for the holiday had you in fact paid the initial $\$ 2,000$ for your driveway to be repaved. ${ }^{25}$

\section{$3 \quad$ Sustaining as a Necessary Condition}

Is sustaining wrongful harm necessary for benefiting-related duties? ${ }^{26}$ To show this, we must demonstrate that beneficiaries do not benefit-with-duty if they do not sustain wrongful harm in either of the ways that we have defined. As an initial support for this claim, consider:

Forced Purchase. Bill steals John's car; neither Bill nor the car can be found. Needing a car, John scours the used car ads and discovers that Susan has advertised her car for sale. John buys Susan's car.

(We assume that the market rules regulating Susan's sale of the car do not violate any of John's claims against that institution.) As in Stolen Car, Susan receives benefits that are causally downstream from Bill's wrongdoing. But it does not seem that Susan has a remedial duty to John. Presumably, this is because Susan has received nothing to which John has a claim, nor does she sustain the violation of any of John's other claims by retaining the proceeds of the sale.

A potentially troublesome class of cases for our account is where it seems that a beneficiary of wrongdoing bears a remedial duty to the victim because the wrongdoer intends to benefit her, whether or not the beneficiary sustains wrongful harm. Contrast the following two cases. ${ }^{27}$

Missed Interview. Wanda and Brent are called to interview for the same job; they are the only candidates. Hank, who has no knowledge of Brent

25 We are grateful to an anonymous reviewer of this journal for suggesting this possibility to us.

26 Beneficiaries of wrongdoing may of course also have duties to the victims on nonbenefiting grounds (e.g., the beneficiary is also the perpetrator of the wrong; the beneficiary and victim are associated in some relevant way; the beneficiary has sufficient capacity to assist the victim). To reiterate, we argue that sustaining wrongful harm is a necessary condition solely for incurring benefiting-related duties, not a necessary condition for incurring remedial duties simpliciter.

27 These cases are presented in Haydar and Øverland, 'Benefiting from Injustice and Poverty Alleviation.' 
or Wanda or the job interview, steals Wanda's car. Consequently, Wanda misses her interview and Brent gets the job.

Missed Interview - Intention. This scenario is the same as Missed Interview, except Hank steals Wanda's car with the intention (unbeknownst to Brent) of securing the job for Brent by making Wanda (the only other candidate) miss her interview.

Brent benefits from Hank's wrongdoing in both cases; but does he incur a remedial duty to Wanda in both cases? We assume that Wanda has no claim to the job-we are uncertain what would have happened had both candidates made their interviews. We also assume that none of Wanda's claims on the hiring practice are violated. Both Wanda and Brent were given fair and accurate notice regarding the time of their interviews and no discrimination was at play in the decision-making process.

Our criterion seems to imply that Brent has no special duty to Wanda in these cases. While some find this plausible in the first case, many express the contrary judgment in the second case. In other words, judgments about these two cases may differ. If Brent does not sustain wrongful harm in any of the ways we enumerate above in either case, then Missed Interview - Intention may be considered a counterexample to our criterion's necessity claim.

This is too quick, however, since our account can reasonably attribute to Brent a remedial duty to Wanda in both cases, while also offering an explanation for the apparent differences between them. Suppose each person has a general claim against their fellows to refrain from obstructing their participation in a fair employment process. In both of these cases, Hank obstructs Wanda's participation in a fair employment process. (Although Hank's obstruction is unwitting in the first case, we do not want to say that one obstructs fair participation only if one knowingly does so.) Given this, in both cases, Brent receives the job in violation of Wanda's claim to unobstructed participation in a fair employment process. Wanda's claim remains unresolved so long as Brent retains the job without working to rectify the situation; at the very least, Brent seems duty-bound to submit himself to a fresh round of interviews. In both cases, Brent's retention of the job sustains wrongful harm in the second of our two senses. With this fact in view, we find it plausible that Brent bears a remedial duty to Wanda in both cases, as our account implies. ${ }^{28}$

28 It bears reiterating here that the duty in question is prima facie. Whether Brent should submit himself to the interviews again might be overturned if the change of position defense applies, or if the general costs of doing so are prohibitive. 
There are reasons why it may appear that these cases differ morally. In Missed Interview - Intention, we might reasonably assume that the beneficiary has an associative connection with the wrongdoer. Why else, after all, would Hank do this to benefit Brent? Further, associative connection with the wrongdoer might be an independently relevant ground for attributing remedial duties. It may also be that in such cases it is hard to eliminate the suspicion that the beneficiary is likely to be in some way complicit in or privy to the wrongdoing that is committed to benefit her. To be sure, the idea that associative connections can ground remedial duties is itself controversial. We are not here affirming that there are such duties but merely suggesting that intuitions about these cases may be being influenced by the common, pre-reflective idea that such connections ground remedial duties. In any event, in those cases where it is clear that there is no associative connection, and where the beneficiary clearly is not privy to the wrongdoing, intention doesn't seem relevant. Interestingly, there is a famous crime that illustrates this. In 1993 a German nationalist named Gunter Parche stabbed Monica Seles in the middle of a tennis match to help Steffi Graf (a German) regain her no.1 ATP ranking. It seems implausible that in this case Graf thereby acquired a remedial duty to Seles that is distinct from remedial duties that other tennis players owe to her in virtue of their benefiting from Seles' absence from competition and declining play. ${ }^{29}$ Hence, merely being the intended beneficiary does not seem directly relevant.

On our view, beneficiaries incur a benefiting-related remedial duty to the victims of wrongdoing if and only if they sustain wrongful harm by retaining the benefits. Our criterion also supports a general explanation for why innocent beneficiaries sometimes incur special duties to the victim: there are relatively stringent requirements against contributing to wrongful harm and sustaining wrongful harm is a distinctive way of contributing to wrongful harm. An innocent beneficiary does not initiate the wrongdoing, nor is she complicit in the initial wrongdoing. However, an innocent beneficiary who sustains wrongful harm contributes to the persistence of the wrongful harm constituted by a violation of a claim held by the victim.

29 Though of course the content of their duties could be affected by the magnitude of the benefits they received as a result of the stabbing. Things might be different if the wrongdoer were Graf's father, in which case she would have a strong associative connection with the wrongdoer that other players on the ATP tour lacked. 
Note that, according to the account that we have defended, beneficiaries bear special remedial duties to the victims of wrongdoing not because they benefit from wrongdoing per se, but because their receipt and retention of the benefits makes a distinctive contribution to maintaining wrongful harm. Contrary to this thought, Pogge argues (in response to Anwander's critique) that there are benefiting-with-duty cases where contributing to wrongdoing is not necessary to generate a special benefiting-related duty to the victim. ${ }^{30}$ He considers the following case:

Sweatshop. Textile workers in an underdeveloped country work for unacceptably low wages and often in unhealthy or dangerous working conditions. Consequently, multinational textile firms can sell their products at lower prices than if they had paid their employees minimally decent wages and provided adequate working conditions. By buying clothing at these low prices, we, the consumers of powerful and affluent countries, are 'taking advantage of injustice' and 'pocket[ing] the gain. ${ }^{31}$

We think Pogge is right to claim that affluent consumers owe a special duty to the wronged textile workers. And it is true that consumers have not initiated the injustice in question-it is not consumers who are paying unacceptably low wages or failing to provide acceptable working conditions. Are these consumers innocent beneficiaries, in our sense? In our world, it is relatively easy to acquire some information, at least, about the manner in which the goods we consume have been produced. Assume for the sake of argument, however, that consumers are non-culpably ignorant of any wrongful harm inflicted by producing these goods. Let's even go so far as to assume (contrary to the connotation of Pogge's phrase 'taking advantage of') that consumers commit no wrongdoing in purchasing the cheap clothing, to ensure that they really are innocent beneficiaries. Even on these assumptions, we do not think that Sweatshop supports the claim that contributing to the wrongful harm from which one benefits is unnecessary for beneficiaries to incur a benefiting-based remedial duty to the textile workers. On Pogge's own account of contributing to harm, the consumers contribute to wrongful harm in Sweatshop in one of the principal ways in which he understands the idea of contributing to wrongful harm-namely, 'cooperation in imposing an institutional order that

30 Thomas Pogge, 'Severe Poverty as a Violation of Negative Duties,' Ethics \& International Affairs 19 (2005), pp. 55-83; Anwander, 'Contributing and Benefiting,' pp. 39-45.

31 Pogge, 'Severe Poverty as a Violation of Negative Duties,' p. 72. 
foreseeably gives rise to avoidable human rights deficits' without compensation. ${ }^{32}$ However, let's put to the side Pogge's particular understanding of what contributing to harm means (or assume that this case involves people who are not linked in any fashion by a shared institutional order). Given all these assumptions, consumers still bear a remedial duty to the textile workers because they receive the benefit of cheap clothing in violation of the workers' claims on the design of institutions governing the labor market and its regulation. In addition, consumers' failure to address the textile workers' hardships (through compensation or lobbying for reform) sustains the wrongful harm so long as textile workers' claims against labor institutions remain in a state of violation. Finally, (all other things being equal) those who contribute to wrong thereby incur special remedial duties to the victims while those who do not contribute do not incur such duties. Thus, consumers bear a duty to the textile workers because, by failing to address their hardships, they sustain, and thereby become contributors to, a wrongful state of affairs. It is not because benefiting from wrongdoing per se violates a duty to the textile workers.

Diagnosing Disagreement

Our criterion can distinguish paradigmatic benefiting-with-duty cases from benefiting-without-duty cases. It can also illuminate somewhat less straightforward cases such as No Promotion or Sweatshop. But there will inevitably be contexts in which many people disagree about whether or not the beneficiary incurs a duty to the victim of the wrongdoing. Consider:

Takeover. Company A acquires Company B in a hostile takeover and closes operations at $\mathrm{B}$. This was done with the intention of decreasing competition and increasing its market share. Instead, Company C, another competitor, gains market share, reaping the benefits of the decreased competition.

Does Company $\mathrm{C}$ have a duty to mitigate the hardships of consumers who are harmed by the decrease in market competition? Does it have a duty to mitigate any hardships experienced by Company B's employees as a result of the takeover? Perhaps. No doubt people's judgments will differ about cases like this. Our account does not resolve these disagreements but delivers a plausible diagnosis of them. Disagreements concerning whether Company C owes

32 Pogge, 'Severe Poverty as a Violation of Negative Duties,' p. 71. 
a special duty to victims of Company A's wrongdoing results from disagreement about the moral character of Company A's conduct, the identity of those harmed by it, and the nature of the relevant claims (if any) that its conduct has violated. In our view, settling the disagreement requires answering several questions first. Do consumers have a claim against Company A or against market regulators to secure some minimal level of market competition (however measured)? Has Company A's acquisition of Company B violated that claim? Do employees or shareholders of Company B have a claim not to be taken over by another company? Has the market institution conferred some undue advantages upon Company $\mathrm{C}$ at the expense of consumers (or employees of Company B, or potential competitors, or...), advantages from which the gains in market share derive? The answers to these questions are likely to be disputed. ${ }^{33}$ We conjecture that much of the disagreement regarding Company C's duties to any candidate victims of Company A's wrongdoing would disappear once we settle our disagreements on these prior issues.

\section{6} Stringency

We have analyzed the category of beneficiary-related duties in terms of the idea of sustaining wrongful harm, which we argue is a distinctive category of contribution to harm. Since the category of sustaining harm is not one that has attracted much attention from philosophers, it is worthwhile to consider the stringency of duties based on this relation. The stringency of a duty can be understood in terms of how it constrains agents, and what it demands of agents who violate these constraints. A duty is constraining to the extent that one cannot justify violating it by appealing to the costs to oneself of adhering to it or by appealing to other valued moral ends that the violation will bring about. In this sense, duties not to do serious harm to innocent people are ordinarily thought to be very constraining, while duties not to be impolite are not. We cannot override the constraint against doing serious harm to an innocent person because respecting it would seriously inconvenience us, whereas we may so override the constraint against being impolite. A duty is demanding insofar as those who have violated it are required to take on quite significant costs to redress the effects of their having done so. Duties against seriously

33 Similar issues also arise in more straightforward compensatory justice cases-Company D wrongs Company E, with knock-on effects for Company F, with whom Company E normally does business. Does Company D owe compensation to Company F? How far down the causal line must we go? 
harming innocent people are ordinarily thought to be quite demanding, whereas moral reasons against being impolite are not.

How constraining are duties not to sustain wrongful harm? In most of the cases we have been discussing, the agents who are now sustaining wrongful harm by having received benefits in violation of other peoples' claims and retaining them were unaware of the situation when the benefits were conferred to them - that is why they are innocent beneficiaries of the wrongful harm. Nevertheless, we can explore (initially, anyway) the nature of the constraints in play by asking what these agents would be required to do were the situation to become fully transparent to them just as the benefit was to be conferred on them. That is, imagine that in Unwanted Car, Susan becomes aware of the fact that Bill's offer to her of his car results from his having stolen John's car. Or suppose that in No Promotion, a male member of the firm who was previously non-culpably ignorant of the discriminatory procedures in the firm becomes aware of them as he learns the news that he is to be promoted to a position through a process that discriminated against female candidates in the firm.

In these cases, it seems that the prospective beneficiaries would be morally required to refuse the benefits and thereby avoid sustaining harms to the victim, even if the costs to them of doing this are significant. Suppose, for example, that in refusing the position that he is offered, the male applicant will have a much harder time rising the ranks of his firm (and of other maledominated firms) than he would have had he instead accepted it (e.g., he gains a reputation as a troublemaker). It is questionable he can appeal to such cost to justify or fully excuse his acceptance of the promotion. And this is so even if he is confident that his refusal to accept the job will mean that some other male candidate will receive the position through the discriminatory process instead. If he does violate his duty and accept the job, it seems that this would change what he is required to do for those harmed by these practices. If for example he accepts the position, we rightly expect him to make greater sacrifices than he otherwise would have to to address the harms resulting from the discriminatory procedures within the firm that conferred benefits on him. In cases like these, duties based on sustaining wrongful harm appear to be relatively constraining and demanding.

Obviously, the stringency of any particular duties based on sustaining wrongful harm will depend in large measure on what is at stake for the person who has been harmed. It may seem implausible that a person should be required to forgo a very large benefit because doing so would sustain a very minor wrongful harm. But this is also true with respect to the constraints on agents arising from duties not to perpetuate harm. That is, the cost to yourself 
to which you can appeal to violate a duty not to do harm to another innocent person will depend on the magnitude of the harm that you would be doing. The same is true of demands: the cost you would be required to take on to redress the harm that you have done if you violate your duty also depends on how severe the harm is. The stringency of duties against sustaining wrongful harm may vary depending on the magnitude of the harm, but they appear (initially, anyway) to be quite stringent when the harm involved is significant.

\section{$7 \quad$ Conclusion}

In this essay we have developed an account of when beneficiaries of wrongdoing have remedial duties to the victims of wrongdoing. And although we have only briefly discussed the content and stringency of such duties, we hope to have provided a starting point for thinking about these issues in more detail. On our account, the stringency of benefiting-related duties will depend on the stringency of duties based on sustaining wrongful harm. We have not offered an exhaustive discussion of duties based on sustaining harm. Rather, we have used the category of sustaining harm to clarify the emerging debate concerning benefiting-related duties. It may be that there is nothing distinctive about sustaining-related duties that involve benefiting from wrongful harm specifically. But we have shown that there is something distinctive about benefiting cases that involve sustaining harm relative to benefiting cases that do not. We have also conjectured that when the wrongful harm that would be sustained by receiving and retaining the benefits is significant, duties arising from this relation are likely to be quite stringent. ${ }^{34}$

34 Earlier versions of this essay were presented at seminars at the Australian National University, the Carnegie Council for Ethics in International Affairs, and at McGill University. We are grateful to the audiences at the seminars, and especially to Arash Abizadeh, Rachael Briggs, Garrett Cullity, Peter Dietsch, Luara Ferracioli, Pablo Gilabert, Bob Goodin, Bashshar Haydar, Robert Kirby, Carl Knight, Holly Lawford-Smith, Seth Lazar, Catherine Lu, Matt Lindauer, Gerhard Øverland, Avia Pasternak, Nic Southwood, Anna Stilz, Lea Ypi and the Editor and two anonymous referees of this journal for comments and suggestions that have helped us to improve it. We gratefully acknowledge the financial support of the Australian Research Council and the Research Council of Norway. 